\title{
Dicarbonyl stress, protein glycation and the unfolded protein response
}

\author{
Naila Rabbani ${ }^{1,2} \cdot$ Mingzhan Xue $^{3} \cdot$ Paul J. Thornalley $^{3}$ (D) \\ Received: 26 January 2021 / Revised: 26 January 2021 / Accepted: 10 February 2021 / Published online: 1 March 2021 \\ (C) The Author(s) 2021
}

\begin{abstract}
The reactive dicarbonyl metabolite, methylglyoxal (MG), is increased in obesity and diabetes and is implicated in the development of insulin resistance, type 2 diabetes mellitus and vascular complications of diabetes. Dicarbonyl stress is the metabolic state of abnormal high MG concentration. MG is an arginine-directed glycating agent and precursor of the major advanced glycation endproduct, arginine-derived hydroimidazolone MG-H1. MG-H1 is often formed on protein surfaces and an uncharged hydrophobic residue, inducing protein structural distortion and misfolding. Recent studies indicate that dicarbonyl stress in human endothelial cells and fibroblasts in vitro induced a proteomic response consistent with activation of the unfolded protein response (UPR). The response included: increased abundance of heat shock proteins and ubiquitin ligases catalysing the removal of proteins with unshielded surface hydrophobic patches and formation of polyubiquitinated chains to encapsulate misfolded proteins; and increased low grade inflammation. Activation of the UPR is implicated in insulin resistance. An effective strategy to counter increased MG is inducing increased expression of glyoxalase-1 (Glo1). An optimized inducer of Glo1 expression, trans-resveratrol and hesperetin combination, normalized increased MG concentration, corrected insulin resistance and decreased low grade inflammation in overweight and obese subjects. We propose that dicarbonyl stress, through increased formation of MG-glycated proteins, may be an important physiological stimulus of the UPR and Glo1 inducers may provide a route to effective suppression and therapy. With further investigation and validation, this may provide key new insight into physiological activators of the UPR and association with dicarbonyl stress.
\end{abstract}

Keywords Methylglyoxal · Glycation · Glyoxalase $\cdot$ Unfolded protein response $\cdot$ Heat shock response $\cdot$ Ubiquitin ligase $\cdot$ Low grade inflammation $\cdot$ Insulin resistance

\section{Dicarbonyl stress}

Dicarbonyl stress is the abnormal accumulation of dicarbonyl reactive metabolites leading to increased protein and DNA

This article belongs to the Topical Collection: Advances in Glycation: from food to human health and disease

Paul J. Thornalley

pthornalley@hbku.edu.qa

1 Department of Basic Medical Science, College of Medicine, QU Health, Qatar University, P.O. Box 2713, Doha, Qatar

2 Biomedical \& Pharmaceutical Research Unit, QU Health, Qatar University, P.O. Box 2713, Doha, Qatar

3 Diabetes Research Center, Qatar Biomedical Research Institute, Hamad Bin Khalifa University, Qatar Foundation, P.O. Box 34110, Doha, Qatar modification contributing to cell and tissue dysfunction in ageing and disease [1]. In the current context, we are considering the impact of protein glycation only. The major dicarbonyl reactive metabolite involved in protein glycation in physiological systems is methylglyoxal (MG). In mammalian metabolism, MG is mainly formed by the spontaneous, trace-level degradation of triosephosphates, glyceraldehyde-3-phosphate and dihydroxyacetonephosphate. Approximately $0.05-0.1 \%$ flux of triosephosphates in glycolysis degrades to MG [2]. Cellular concentrations are low, typically $2-4 \mu \mathrm{M}$, but $\mathrm{MG}$ is a highly reactive metabolite and modifies proteins to form argininederived hydroimidazolone, MG-H1 - the major advanced glycation endproduct (AGE) formed in physiological systems [3]. The concentration of MG is maintained at these low levels by metabolism by glyoxalase 1 (Glo1) of the glyoxalase system. The glyoxalase system is comprised of two enzymes, Glo1 and glyoxalase 2 (Glo2) and a catalytic amount of reduced glutathione (GSH). Glo1 catalyses the conversion of the hemithioacetal 
formed spontaneously from MG and GSH to S-Dlactoylglutathione and Glo2 catalyses the onward conversion of this to D-lactate, reforming GSH consumed in the Glo1 catalysed step - Fig. 1a. The glyoxalase system is present in all cells and, by efficient metabolism of MG, suppresses the reaction of MG with protein to low tolerable levels [4]. The steady concentration of MG and related protein glycation is increased in aging, health disorders and disease where it likely contributes to decline in health and pathogenesis. This is evident in obesity, diabetes and vascular complications of diabetes (diabetic kidney disease, diabetic retinopathy, diabetic neuropathy and diabetic cardiovascular disease), cardiovascular disease and end stage renal disease - reviewed in [4-6]. Therapeutic agents in development to alleviate dicarbonyl stress, particularly inducers of Glo1 expression or "Glo1 inducers", have shown promise in clinical trial $[2,5]$. Recent research has implicated the accumulation of proteins glycated by MG with activation of the UPR and downstream inflammatory processes $[7,8]$. In experimental studies, the UPR may be activated by inhibition of enzymatic N-linked glycosylation of proteins with tunicamycin - an inhibitor of UDP-N-acetylglucosamine: dolichyl-phosphate $\mathrm{N}$-acetylglucosaminephosphotransferase [9]. However, this is not a physiological activator of the UPR. Glycation has been considered to be a contributory factor to protein misfolding and provide substrates for the UPR but the mechanisms remained unclear [10]. In this review, we describe recent advances and how MG glycation provides a challenge to protein homeostasis and physiological substrates for the UPR.

\section{Effect of methylglyoxal modification of proteins on protein folding}

MG is an arginine-directed glycating agent, forming mainly MG-H1. Formation of MG-H1 produces loss of charge and an
$18 \%$ increase in molecular volume of the precursor arginine residue [11] - Fig. 1b. This produces loss of all electrostatic interactions. Physicochemical and molecular dynamic studies of proteins indicate arginine salt bridge interactions, particularly glu ${ }^{-} \mathrm{arg}^{+}$pairs, have a key role in kinetics and thermodynamic stability of protein folding, locking in to correct folding conformations [12]. Arginine residues are also common in cation- $\pi$ interactions of the guanidinium sidechain cation with the aromatic $\pi$-electron distribution of tyrosine sidechains, providing intermolecular bonding at protein-protein interfaces [13]. All of these interactions are lost with modification by MG.

Regarding hydrophobicity, we applied the empirical prediction for hydrophobicity of amino acids from experimental measurements of the transfer energy (Etr) [14]. This suggests that Etr values for arginine and MG-H1 residues are 17.3 and 11.7, respectively, and related Eisenberg hydrophobicity $<$ $H>$ values are -2.5 and -0.6 , respectively. This indicates formation of MG-H1produces a profound shift towards hydrophobicity; the closest uncharged amino acids with hydrophobicities similar to that predicted for MG-H1 are asparagine and glutamine with $\langle H\rangle$ values of -0.78 and -0.85 , respectively. When MG modification occurs on arginine residues on the surface of proteins, as it typically does - often targeting residues with low microscopic $\mathrm{pK}_{\mathrm{a}}$ which are activated towards modification $[15,16]$, there is creation of a hydrophobic residue on the surface of the protein substrate. This is different to the native protein structure where hydrophobic residues are often buried inside globular proteins or "shielded". Surface unshielded hydrophobic residues are a key signature of misfolded proteins and a recognition feature leading to them being targetted for ubiquitination and degradation [17].

Initial studies of MG glycated proteins showed structural distortion and instability of modified proteins. In the assessment of the effect of MG modification on the
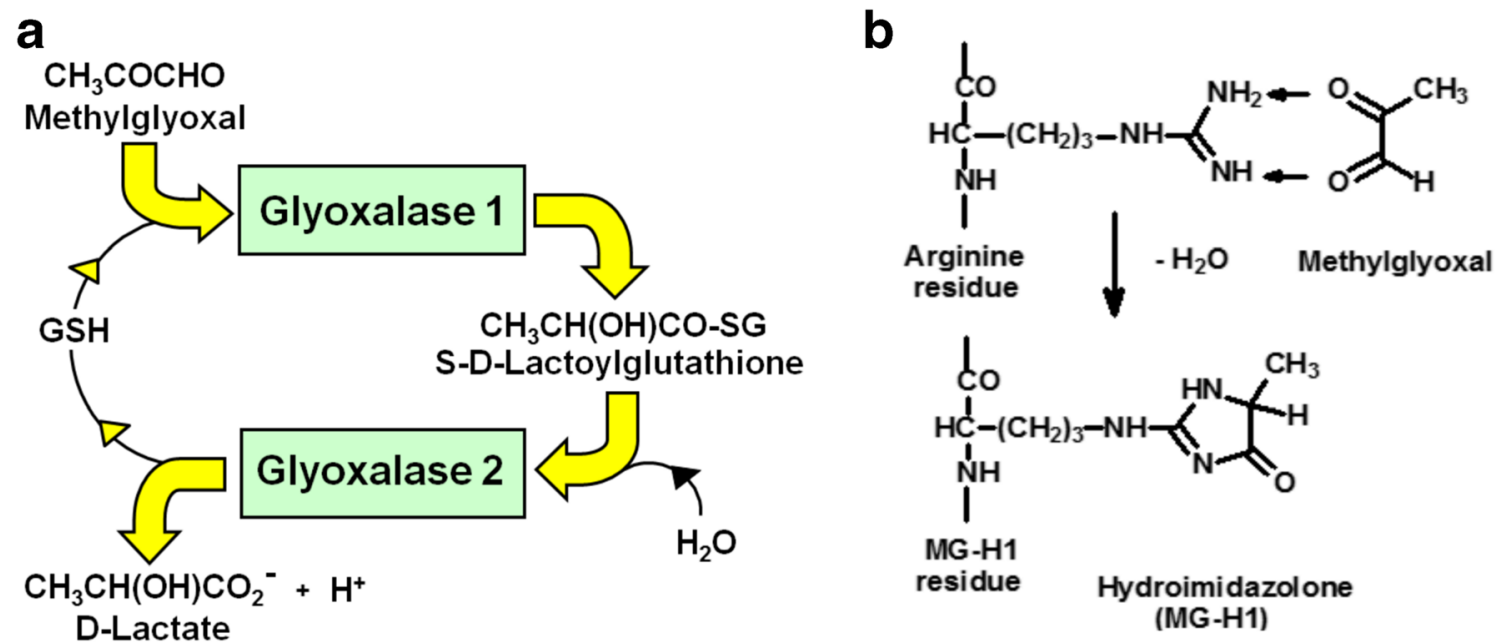

Fig. 1 Major pathways of metabolism and glycation of methylglyoxal. a Metabolism of MG by the glyoxalase system. b Formation of hydroimidazolone MG-H1 from arginine residues 
structure and folding of proteins in vivo, it is important to reflect that proteins are minimally modified by $\mathrm{MG}$ with usually $1-5 \%$ of protein modified [18]. Early studies of albumin and other proteins prepared in vitro with high extent of MG modification - often $>20$ modifications per protein molecule - were a poor structural and functional model of proteins glycated by $\mathrm{MG}$ in vivo $[19,20]$. For human serum albumin, low level modification by MG led to preferential modification of Arg410 by $\mathrm{MG}$ to form a MG-H1 residue. Molecular graphics analysis of the MG-modified domain indicated that hydrogen bonding of this residue to Asn-391 was abolished and the proximate helical structure, helix 3Ah2, was distorted such that Arg-410 and Tyr-411 swung away from Asn-391, increasing the spatial separation of Asn-391 and Arg-410 [15]. Apolipoprotein B100 (apoB100), the major protein of low density lipoprotein (LDL) and very low density lipoprotein (VLDL) particles, is susceptible to MG modification in vivo [21]. Arg-18 was preferentially modified by MG in apoB 100 . A molecular graphics prediction of the structure of the MG-modified apoB100 was made based on structural similarity of the MG-modified domain of lipovitellin. This residue lies at the terminal focus of a lattice of seven parallel $\beta$-strands. Conversion of this residue to MG-H1 disrupted and distorted interactions with all seven $B$-strands and produced surface exposure of a proteoglycan binding domain [22]. Preferential sites of $M G$ modification of apolipoprotein A-1 of high density lipoprotein (HDL) were Arg-27 and Arg-123. Conversion of Arg-27 to MG-H1 abolished the salt bridge interaction with Asp-29, and modification at Arg-123 to MG-H1 in helix 5 abolished the salt bridge interaction with Glu120 of helix 4, with loss of interhelical bonding and related structural stability. MG modification of apolipoprotein A-1 was associated with decreased HDL stability and half-life [23]. We have listed and identified many other proteins susceptible to MG modification in our recent reports $[7,8,16]$.

These characteristics of the arginine to MG-H1 transition and MG-modified proteins suggest that $\mathrm{MG}$ glycation may induce protein structural distortion and misfolding. Modification by glucose to form Nterminal and lysine sidechain fructosamine derivatives, $\mathrm{N}_{\alpha}$-(1-deoxy-D-fructos-1-yl)amino acid and $\mathrm{N}_{\varepsilon}$-(1-deoxy-D-fructos-1-yl)lysine (FL), respectively, may induce much lower structural distortion and misfolding because the cationic charge and all electrostatic interactions are retained. The fructosyl moiety is also hydrophilic [11]. MG-modified proteins may therefore present a challenge to cell protein homeostasis and the protein quality control system, the UPR, may become activated for their removal.

\section{Activation of the unfolded protein response in dicarbonyl stress}

Incubation of human aortal endothelial cells (HAECs) in high glucose concentration in vitro is an established model of endothelial cell dysfunction in hyperglycemia associated with diabetes. We found the cellular concentration of MG and MGmodified proteins was increased ca. 2-fold in HAECs incubated in $20 \mathrm{mM}$ glucose, compared to $5 \mathrm{mM}$ glucose normoglycemic control. MG concentration was increased in model hyperglycemia by increase in flux of glucose metabolism and concomitant increase in flux of MG formation, synergizing with decrease in Glo1 activity, linked to increased proteolysis [7]. To explore the mechanism of increased glucose metabolism in high glucose concentration - subsequently found to be due to glucoseinduced stabilization of hexokinase-2 (HK2) to proteolysis, we analyzed and quantified the cytoplasmic proteome. The mean number of proteins identified in low and high glucose concentration was 1894 . We found 331 proteins were upregulated with increased abundance in high glucose concentration cultures. There was increased of abundance of proteins in glycolysis and gluconeogenesis, which may be expected given the increased glucose metabolism through glycolysis and also into gluconeogenesis through metabolic channeling when HK2 is detached from mitochondria [7]. There was, however, also enrichment of proteins of the heat shock response - part of the UPR. Abundance increases in 8 heat shock proteins (HSPs) were recorded: HSPA8, HSP70 1A and 1B, HSPA1L, HSP105 kDa and HSPA9 (GRP75), HSPA5 (GRP78) and BAG5. These are chaperone proteins with expression increases by heat shock factor-1 (HSF-1) catalysing the refolding of proteins or recruiting ubiquitin E2 ligases for protein degradation by chaperone-assisted ubiquitin-proteasome pathway and autophagy. There were an additional 4 proteins of increased abundance of the heat shock response: replication protein A1 (RFA1), nucleoporin $214 \mathrm{kDa}$ (NUP214), nuclear pore complex protein $133 \mathrm{kDa}$ (NUP133) and nuclear pore complex protein $358 \mathrm{kDa}$ (NUP358 - also known as RANBP2). RFA1 binds to HSF-1, assisting access to nucleosomal DNA by recruiting histone chaperone, facilitates chromatin transcription (FACT), which displaces the histone H2A-H2B dimer for transactivational activity of HSF-1 for increased HSP expression [24]. Increased nuclear pore protein abundance facilitates increased nuclear export of mRNA of HSPs for increased expression of these proteins in the response to proteotoxic stress [25] (Table 1).

We envisage that increased expression of HSPs reflects increased activation of HSF-1 in response to MG-driven proteotoxic stress. Inactive HSF-1 monomers complex with HSP40, HSP70, HSP90 and the chaperonin TCP-1 ring complex (TRiC) - Fig. 2. TriC chaperonins were also a target of MG modification [7]. Displacement of HSF-1 from this complex leads to its oligomerization and nuclear translocation for 
Table 1 Proteins of regulation of HSF1-mediated heat shock response increased in HAECs in high glucose concentration in vitro

\begin{tabular}{|c|c|c|c|}
\hline Protein (abbreviations) & Location & Function & Reference \\
\hline $\begin{array}{l}\text { Heat shock cognate } 71 \mathrm{kDa} \text {, (HSPA } 8 \text {, } \\
\text { HSP73) }\end{array}$ & Cytosol, nucleus & Chaperone-mediated autophagy. Binds with ubiquitin E2 ligase, CHIP & {$[68,69]$} \\
\hline $\begin{array}{l}\text { Heat shock protein } 70 \mathrm{kDa} \text { protein } 1 \\
\text { (HSP701A, HSP1A, HSP72 }\end{array}$ & Cytosol, nucleus & $\begin{array}{l}\text { Chaperone. Binds CHIP, Ubc } 4 / 5 \text { family of E2 enzymes and HUWE1. } \\
\text { Chaperone-assisted ubiquitin-proteasome pathway and autophagy }\end{array}$ & {$[70]$} \\
\hline $\begin{array}{l}\text { Heat shock protein } 70 \mathrm{kDa} \text { protein } 2 \\
\quad(\mathrm{HSP} 701 \mathrm{~B}, \mathrm{HSP} 1 \mathrm{~B})\end{array}$ & Cytosol, nucleus & $\begin{array}{l}\text { Chaperone. Binds CHIP, Ubc4/5 family of E2 enzymes and HUWE1. } \\
\text { Chaperone-assisted ubiquitin-proteasome pathway and autophagy }\end{array}$ & {$[70]$} \\
\hline Heat shock 70 kDa protein 1L (HSPA1L) & Cytosol, nucleus & Chaperone & {$[71]$} \\
\hline $\begin{array}{l}\text { Heat shock } 105 \mathrm{kDa} \text { (HSP105, HSPH1, } \\
\text { HSP110) }\end{array}$ & Cytosol, nucleus & $\begin{array}{l}\text { Chaperone Interacts with HSC70 and HSP90. Chaperone-assisted } \\
\text { ubiquitin-proteasome pathway and autophagy. }\end{array}$ & {$[72]$} \\
\hline $\begin{array}{l}\text { Glucose regulated protein } 75 \mathrm{kDa}(\mathrm{GRP} 75, \\
\text { HSPA9, MOT2, PBP74) }\end{array}$ & $\begin{array}{r}\text { Mitochondria, } \\
\text { cytosol, ER }\end{array}$ & Chaperone & {$[73]$} \\
\hline $\begin{array}{l}\text { Glucose regulated protein } 78 \mathrm{kDa}(\mathrm{GRP} 78, \\
\text { HSPA5, BIP, MIF2) }\end{array}$ & ER & $\begin{array}{l}\text { Chaperone Activates activating transcription factor } 6 \text { (ATF6), PERK and } \\
\text { IRE1 } \alpha\end{array}$ & {$[73]$} \\
\hline Bcl-2- associated athanogene 5 (BAG5) & Cytosol, nucleus & Chaperone. CHIP Hsp70/Hsc70 & {$[74]$} \\
\hline Replication Protein A1 (RFA1) & Nucleus & $\begin{array}{l}\text { Assists HSF1 to access nucleosomal DNA for transcription regulation of } \\
\text { HSPs. }\end{array}$ & {$[24]$} \\
\hline Nucleoporin 214 kDa (NUP214) & $\begin{array}{l}\text { Nuclear } \\
\text { membrane }\end{array}$ & $\begin{array}{l}\text { Part of the nuclear pore complex. critical role in nucleocytoplasmic } \\
\text { transport }\end{array}$ & {$[75]$} \\
\hline $\begin{array}{l}\text { Nuclear pore complex protein } 133 \mathrm{kDa} \\
\text { (NUP133) }\end{array}$ & $\begin{array}{l}\text { Nuclear } \\
\text { membrane }\end{array}$ & $\begin{array}{l}\text { Part of the nuclear pore complex. critical role in nucleocytoplasmic } \\
\text { transport }\end{array}$ & {$[75]$} \\
\hline $\begin{array}{l}\text { Nuclear pore complex protein } 358 \mathrm{kDa} \\
\text { (NUP358, RANBP2) }\end{array}$ & $\begin{array}{l}\text { Nuclear } \\
\text { membrane }\end{array}$ & $\begin{array}{l}\text { SUMO1 E3 ligase. Controls the shuttling of proteins between the nuclear } \\
\text { and cytoplasm compartments of the cell }\end{array}$ & {$[75]$} \\
\hline
\end{tabular}

transactivational response, where HSF-1 has several posttranslational modifications (ser and thr phosphorylation, acetylation, ubiquitin and small ubiquitin-like modifier (SUMO)) and binds to RFA1. Later, it re-associates in monomeric inactive form in the chaperonin/HSP complex [26]. MG-modified proteins are thereby likely funneled through the HSP pathway, through the sensing and binding of an unshielded, surface hydrophobic MG-H1 residue. Where MG-modified protein cannot be refolded to shield MG-H1 from the surface - we assume this is likely in most cases, they are targeted for degradation.

In the study of HAECs, in high glucose concentration and dicarbonyl stress, the abundance of 3 ubiquitin protein ligases were increased: E2/E3 hybrid ubiquitin-protein ligase UBE2O $(+47 \%)$; E3 ligase, HECTD1 $(+34 \%)$; and ligase E3C, UBE3C $(+21 \%)$ [7]. UBE2O acts as an autonomous

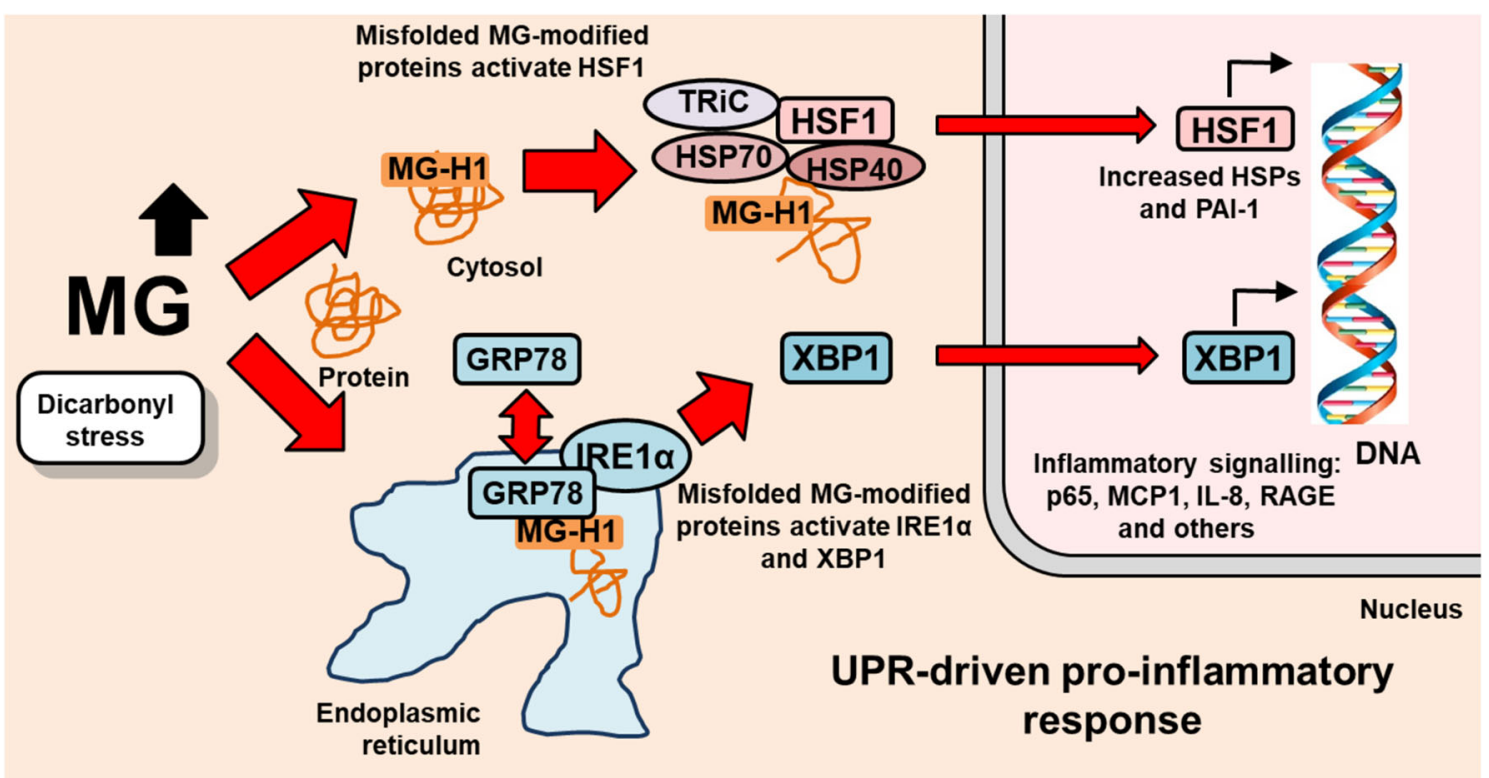

Fig. 2 Activation of the cytosolic and endoplasmic reticulum UPR by misfolded MG-modified proteins. Schematic diagram of the mechanisms of activation of the unfolded protein responsive and pro-inflammatory response by dicarbonyl stress and increased glucose metabolism in endothelial cells in hyperglycemia. Adapted from [7] 
quality control factor in protein homeostasis by recognition and elimination of unassembled protein subunits of protein complexes with proximate basic and hydrophobic patches on unassembled proteins [27]. HECTD1 interacts with HSP90 to regulate its cell location and degradation [28]. UBE3C improves degradation of protein fragments that arise by incomplete proteolysis of substrates by the proteasome [29]. In hyperglycemia-induced dicarbonyl stress in periodontal ligament fibroblasts (PDLFs), there was abundance of ubiquitin ligases: HUWE1 (+460\%), CHIP (+104\%) and RNF31 (+ $97 \%)$ [8]. HUWE1 is an E3 ubiquitin ligase targeting substrates with unshielded, hydrophobic segments [30] - befitting of MG-modified proteins. Interestingly, conditional knockout of HUWE1 in pancreatic beta-cells of mice accelerated the agedependent decline of insulin secretion and glucose homeostasis [31], which may mimic the effect of chronic dicarbonyl stress in clinical insulin resistance [32]. CHIP, as mentioned above, is a functional partner of HSP70. RNF31, also called heme-oxidized iron regulatory protein ubiquitin ligase-1-interacting protein (HOIP), is part of the linear ubiquitin chain assembly complex (LUBAC). Activation of LUBAC has a key role in proteotoxic stress, producing ubiquitin chains on misfolded proteins which wrap round it, preventing undesirable interactions which may otherwise contribute to pathogenesis [33]. The increased ubiquitination response found in dicarbonyl stress is, therefore, a response to unexpected surface hydrophobic patches on proteins and peptides, increasing their degradation and guarding against unwanted interactions such as aggregation. It is a response to change in surface physicochemical properties and related misfolding of proteins rather than a response to a specific chemical structure of the MG moiety of MG-glycated proteins (Table 2).

A further remarkable finding in the study of dicarbonyl stress in PDLFs was the finding of increased Golgi-to-ER retrograde traffic of proteins. This is part of the cell response to increased misfolded proteins: misfolded proteins are returned to the ER for refolding [34, 35]. Activation of the UPR is considered to have a major effect on shuttling of proteins between the Golgi apparatus and the ER where the flux of protein cargo may influence the vesicular COPI-dependent and tubular COPI-independent retrograde protein transport [36, 37]. Repeated shuttling of proteins between the ER and Golgi apparatus is considered to be part of the quality control mechanisms to support protein homeostasis. Misfolded proteins are returned from the Golgi apparatus to ER for correction of protein misfolding; and, for covalently-modified and proteins such as MG-modified proteins where misfolding fails, proteins are diverted for proteolysis, ER-associated protein degradation (ERAD) - Fig. 3.

\section{Inflammatory signalling in dicarbonyl stress via the unfolded protein response}

Increased low grade inflammation is a consequence of activation of the UPR. All three main pathways of the UPR, ATF6, PERK and XBP-1, have been linked to inflammatory signalling [38, 39]. A pathway where dicarbonyl stress may be particularly implicated is XBP-1 related activation of histone-lysine N-methyltransferase SETD7. XBP-1 activation induces expression of SETD7 which increases methylation of lysine 4 of histone 3 on NF-kB p65 promoter, p65 expression and binding activity. This epigenetic signal was associated with upregulation of NF-kB inflammatory system with subsequent transcription of inflammatory gene expression: increased intercellular cell adhesion molecule-1 (ICAM-1), monocyte chemoattractant protein-1 (MCP-1), receptor for advanced glycation endproducts (RAGE), interleukin-8 (IL-8) and GRP78 [40-42]. A previous remarkable finding was that this proinflammatory signaling mediated by SETD7 and activated by transient and persistent model hyperglycemia was inhibited by overexpression of Glo1 [43].
Table 2 Ubiquitin ligases increased in cellular models of dicarbonyl stress in vitro

\begin{tabular}{|c|c|c|}
\hline $\begin{array}{l}\text { Ubiquitin } \\
\text { ligase }\end{array}$ & Function & Reference \\
\hline UBE2O & $\begin{array}{l}\text { Autonomous quality control factor in protein homeostasis by recognition and } \\
\text { elimination of unassembled protein subunits of protein complexes with } \\
\text { proximate basic and hydrophobic patches on unassembled proteins. }\end{array}$ & {$[27]$} \\
\hline HECTD1 & Regulates cellular location and degradation of HSP90. & {$[28]$} \\
\hline UBE3C & $\begin{array}{l}\text { Improves degradation of protein fragments that arise by incomplete proteolysis of } \\
\text { substrates by the proteasome. }\end{array}$ & [29] \\
\hline HUWE1 & Targets substrates with unshielded, hydrophobic segments. & {$[30]$} \\
\hline CHIP & Functional partner of HSP70. & {$[69]$} \\
\hline $\begin{array}{l}\text { RNF31 } \\
\text { (HOIP) }\end{array}$ & $\begin{array}{l}\text { Part of the LUBAC, producing ubiquitin chains on misfolded proteins which wrap } \\
\text { round the substrate, preventing undesirable interactions contributing to } \\
\text { pathogenesis, e.g. aggregation. }\end{array}$ & {$[33]$} \\
\hline
\end{tabular}




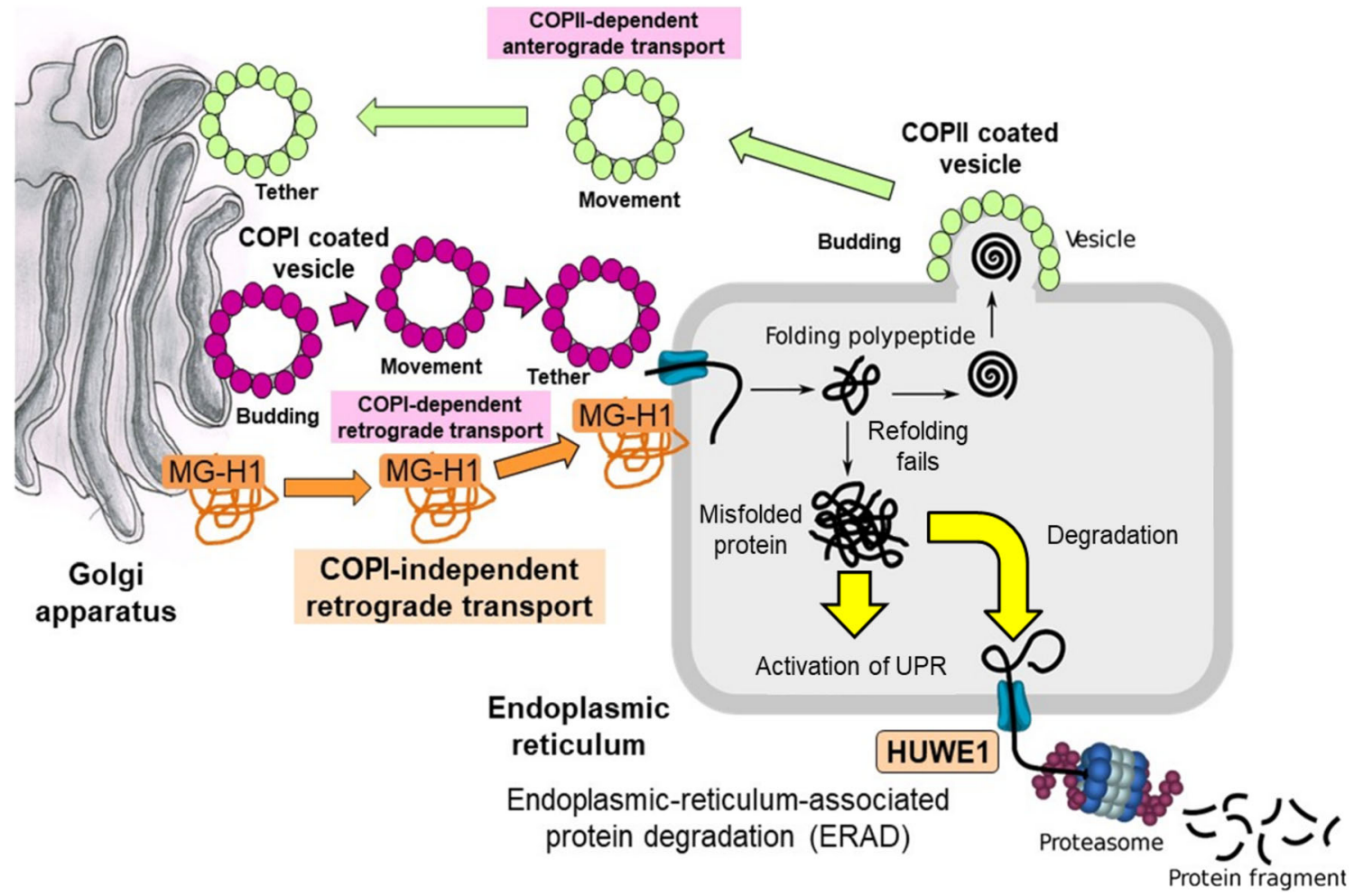

Fig. 3 Bidirectional transport between the ER and the Golgi mediated by COPII and retrograde transport mediated by COPI-dependent -independent carriers. Schematic diagram shows budding, movement, tethering, and uncoating and fusion of COPII and COPI carriers. COPI-independent

This suggests that the XBP1/SETD7 pathway of epigenetic signaling for increased low-grade inflammation may be a pathogenic consequence of activation of the UPR by dicarbonyl stress, and that the key inflammatory signaling pathway in response to dicarbonyl stress is via XBP-1.

Key to activation of XBP-1 is chaperone GRP-78 activation of the serine/threonine kinase inositol-requiring enzyme-1alpha (IRE1 $\alpha$ ). This leads to the stimulation of endoribonuclease activity of IRE $1 \alpha$ and the splicing of XBP1 mRNA to form functionally active XBP-1. A further consequence of activation of IRE $1 \alpha$ is decrease of micro-RNA-17, miR-17, and stabilization of thioredoxin interacting protein (TXNIP) mRNA and increased expression of TXNIP [44]. TXNIP decreases glucose uptake by skeletal muscle and pancreatic beta-cell mass and insulin secretion and increases hepatic gluconeogenesis. It is thereby a major mediator of insulin resistance [45-47]. This and related UPR stimulated low grade inflammation likely contributes to pathogenesis in insulin resistance, obesity, type 2 diabetes mellitus (T2DM), non-alcoholic fatty liver disease (NAFLD), chronic kidney disease, cardiovascular disease and agelinked decline of respiratory function [48-58] - Fig. 2. transport of MG-modified proteins likely involves vesicular transport along connecting tubules [36, 37]. After return to the ER, MG-modified proteins meet the substrate preference for ubiquitination by HUWE1 and degradation

\section{Glyoxalase 1 inducer therapeutics}

The above coverage provides evidence and argument for dicarbonyl stress providing physiological substrate, MGmodified proteins, for the UPR. With this potential advance in understanding of pathogenic mechanism, it is important to identify and develop pharmacological mechanisms to exploit the advance for effective intervention with novel drug therapy. An effective and efficient strategy to counter dicarbonyl stress is development of Glo1 inducers. Glo1 inducers increase Glo1 expression and activity, correct increased MG concentration and formation of MG glycated proteins, and thereby cut off activation of the UPR at source. Glo1 inducers have important advances over other potential pharmacological strategies to decrease $\mathrm{MG}$ - as reviewed [32]. We identified an optimum Glo1 inducer available from dietary bioactive compounds which activate transcription factor Nrf2. GLO1 is an antioxidant response element (ARE) linked gene with basal and inducible expression regulated by Nrf2 [59]. We screened individual and synergistic binary combinations of dietary bioactives compounds for induction of Glo1 expression using a GLO1-ARE luciferase reporter assay. The optimum Glo1 inducer was a 
combination of trans-resveratrol and hesperetin, tRES-HESP. Induction of Glo1 expression was validated at mRNA and protein levels in human cell cultures - primary cultures of HAECs and BJ fibroblasts, and the hepatocyte-like HepG2 cell line [5].

For clinical evaluation, we performed a double-blind, randomised, placebo-controlled crossover study in overweight and obese subjects with 8 weeks treatment with tRES-HESP; one capsule daily before breakfast containing $90 \mathrm{mg}$ tRES and $120 \mathrm{mg}$ HESP. For target pharmacology, we found increased expression and activity of Glo1, decreased plasma MG concentration and decreased total body flux of formation of MG-H1. In evaluation of effects on dysglycemia and insulin resistance, we found decreased fasting plasma glucose (FPG) and postprandial plasma glucose and correction of insulin resistance by tRES-HESP; placebo had no effect. We also found improved arterial dilatation and decreased vascular inflammation marker, soluble ICAM1 [5]. Comparison of the effect of tRES-HESP in overweight and obese subjects to that of metformin and Orlistat - potential alternative treatments targeting other pathogenic mechanisms - on similar subjects groups in intervention trials suggested the effect of tRESHESP on glycaemic control exceeds that of metformin and matches that of Orlistat $[60,61]$. The improvement in insulin resistance is comparable to that achieved with extreme weight loss with gastric band surgery in morbid obesity [62]. tRESHESP may also improve the function of pancreatic beta-cells [5]. Decrease in FPG in the normal range is associated with reduced risk of developing T2DM [63]. The Glo1 inducer formulation could be a suitable treatment for improved metabolic and vascular health in overweight and obese populations [5]. Insulin resistance is also linked to NAFLD, chronic kidney disease, cardiovascular disease, decline of respiratory function and aging [48-58] - likely through increased low grade inflammation linked to hyperinsulinemia [64]. With a safe and effective treatment of insulin resistance, prevention and early-stage reversal of T2DM and other insulin resistance linked pathology and mortality may be improved. There is currently no pharmacotherapy specifically targeting mechanisms of insulin resistance - although several pharmacological approaches are in development $[65,66]$. Glo1 inducers, therefore, offer an improved, safe and effective route to novel insulin sensitizing agents [5].

\section{Concluding remarks}

The UPR plays a vital role in proteostasis through surveillance of quality of the proteome, sensing damaged and misfolded proteins and activating processes of protein refolding for repair or proteolysis for removal [67]. With recent studies on physiological dicarbonyl stress and identification of the proteomic response to it, protein glycation by MG has emerged as a potential key physiological activator of the UPR. Further investigation and application of Glo1 inducer therapeutics are required. If confirmed, key advances in understanding of physiological substrates and activators of the UPR in aging and disease may emerge where increase of Glo1 expression may be a key pharmacological target.

Abbreviations AGE, Advanced glycation endproduct; ApoB100, Apolipoprotein B100; ARE, Antioxidant response element; ATF6, Activating transcription factor 6; COPI, Coatomer protein I; COPII, Coatomer protein II; ER, Endoplasmic reticulum; ERAD, Endoplasmic reticulum-associated protein degradation; FACT, Facilitates chromatin transcription; FL, NE-(1-Deoxy-D-fructos-1-yl)lysine; FPG, Fasting plasma glucose; Glo1, Glyoxalase 1; Glo2, Glyoxalase 2; GRP78, Glucose regulated protein $78 \mathrm{kDa}$; GSH, Reduced glutathione; HAECs, Human aortal endothelial cells; HDL, High density lipoprotein; HOIP, Hemeoxidized iron regulatory protein ubiquitin ligase-1-interacting protein; HSF-1, Heat shock factor-1; HSP, heat shock protein; ICAM-1, Intercellular cell adhesion molecule-1; IL-8, Interleukin-8; IRE1 $\alpha$, Inositol-requiring enzyme-1alpha; LDL, Low density lipoprotein; LUBAC, Linear ubiquitin chain assembly complex; MCP-1, Monocyte chemoattractant-1; MG, Methylglyoxal; MG-H1, N $\delta$-(5-Hydro-5-methyl-4-imidazolon-2-yl)ornithine; NAFLD, Non-alcoholic fatty liver disease; Nrf2, Nuclear factor erythroid 2-related factor 2; NUP133, Nuclear pore complex protein $133 \mathrm{kDa}$; NUP214, Nucleoporin 214 $\mathrm{kDa}$; NUP358, nuclear pore complex protein $358 \mathrm{kDa}$; PDLF, Periodontal ligament fibroblast; PERK, Protein kinase RNA-like endoplasmic reticulum kinase; RAGE, Receptor for advanced glycation endproducts; RANBP2, Ras-related nuclear binding protein 2; RFA1, Replication protein A1; SETD7, Histone-lysine N-methyltransferase; SUMO, Small ubiquitin-like modifier; T2DM, Type 2 diabetes mellitus; tRES-HESP, trans-Resveratrol and hesperetin combination; TRiC, Chaperonin T- complex protein-1 ring complex; TXNIP, Thioredoxin interacting pro- tein; UPR, Unfolded protein response; VLDL, Very low density lipopro- tein; XBP-1, X-box binding protein 1

Acknowledgements NR thanks Qatar University and MX and PJT thank Qatar Foundation for funding for their glycation research.

Author contributions NR and PJT wrote the manuscript. All authors checked, amended and approved the manuscript.

Funding Open access funding provided by the Qatar National Library.

\section{Declarations}

Conflict of interest The authors declare that they have no conflicts of interest.

Ethical approval This article does not contain any studies with human participants or animals performed by any of the authors.

Open Access This article is licensed under a Creative Commons Attribution 4.0 International License, which permits use, sharing, adaptation, distribution and reproduction in any medium or format, as long as you give appropriate credit to the original author(s) and the source, 
provide a link to the Creative Commons licence, and indicate if changes were made. The images or other third party material in this article are included in the article's Creative Commons licence, unless indicated otherwise in a credit line to the material. If material is not included in the article's Creative Commons licence and your intended use is not permitted by statutory regulation or exceeds the permitted use, you will need to obtain permission directly from the copyright holder. To view a copy of this licence, visit http://creativecommons.org/licenses/by/4.0/.

\section{References}

1. Rabbani, N., Thornalley, P.J.: Dicarbonyl stress in cell and tissue dysfunction contributing to ageing and disease. Biochem. Biophys. Res. Commun. 458(2), 221-226 (2015)

2. Rabbani, N., Xue, M., Thornalley, P.J.: Methylglyoxal-induced dicarbonyl stress in aging and disease: first steps towards glyoxalase 1-based treatments. Clin. Sci. 130, 1677-1696 (2016)

3. Thornalley, P.J.: Dicarbonyl intermediates in the Maillard reaction. Ann. N. Y. Acad. Sci. 1043, 111-117 (2005)

4. Rabbani, N., Xue, M., Thornalley, P.J.: Dicarbonyls and glyoxalase in disease mechanisms and clinical therapeutics. Glycoconj. J. 33, 513-525 (2016). https://doi.org/10.1007/s10719-016-9705-z

5. Xue, M., Weickert, M.O., Qureshi, S., Ngianga-Bakwin, K., Anwar, A., Waldron, M., Shafie, A., Messenger, D., Fowler, M., Jenkins, G., Rabbani, N., Thornalley, P.J.: Improved glycemic control and vascular function in overweight and obese subjects by glyoxalase 1 inducer formulation. Diabetes 65(8), 2282-2294 (2016)

6. Schalkwijk, C., Stehouwer, C.D.: Methylglyoxal, a highly reactive dicarbonyl compound, in diabetes, its vascular complications and other age-related diseases. Physiol. Rev. 100, 407-461 (2019). https://doi.org/10.1152/physrev.00001.2019

7. Irshad, Z., Xue, M., Ashour, A., Larkin, J.R., Thornalley, P.J., Rabbani, N.: Activation of the unfolded protein response in high glucose treated endothelial cells is mediated by methylglyoxal. Sci. Rep. 9, 7889 (2019). https://doi.org/10.1155/2018/5642148

8. Ashour, A., Xue, M., Al-Motawa, M., Thornalley, P.J., Rabbani, N.: Glycolytic overload-driven dysfunction of periodontal ligament fibroblasts in high glucose concentration, corrected by glyoxalase 1 inducer. BMJ Open Diabetes Res. Care 8(2), e001458 (2020). https://doi.org/10.1136/bmjdrc-2020-001458

9. Yoo, J., Mashalidis, E.H., Kuk, A.C.Y., Yamamoto, K., Kaeser, B., Ichikawa, S., Lee, S.-Y.: GlcNAc-1-P-transferase-tunicamycin complex structure reveals basis for inhibition of N-glycosylation. Nat. Struct. Mol. Biol. 25(3), 217-224 (2018). https://doi.org/10. 1038/s41594-018-0031-y

10. Goldberg, A.L.: Protein degradation and protection against misfolded or damaged proteins. Nature 426, 895-899 (2003)

11. Rabbani, N., Thornalley, P.J.: Dicarbonyl proteome and genome damage in metabolic and vascular disease. Biochem. Soc. Trans. 42(2), 425-432 (2014)

12. Meuzelaar, H., Vreede, J., Woutersen, S.: Influence of Glu/Arg, Asp/Arg, and Glu/Lys salt bridges on $\alpha$-helical stability and folding kinetics. Biophys. J . 110(11), 2328-2341 (2016). https://doi.org/ 10.1016/j.bpj.2016.04.015

13. Crowley, P.B., Golovin, A.: Cation-pi interactions in proteinprotein interfaces. Proteins: Struct., Funct., Bioinf. 59(2), 231239 (2005)

14. Lins, L., Charloteaux, B., Heinen, C., Thomas, A., Brasseur, R.: "De novo" design of peptides with specific lipid-binding properties. Biophys. J. 90(2), 470-479 (2006)

15. Ahmed, N., Dobler, D., Dean, M., Thornalley, P.J.: Peptide mapping identifies hotspot site of modification in human serum albumin by methylglyoxal involved in ligand binding and esterase activity. J. Biol. Chem. 280(7), 5724-5732 (2005)

16. Rabbani, N., Ashour, A., Thornalley, P.J.: Mass spectrometric determination of early and advanced glycation in biology. Glycoconj. J. 33, 553-568 (2016). https://doi.org/10.1007/s10719-016-9709-8

17. Fredrickson, E.K., Rosenbaum, J.C., Locke, M.N., Milac, T.I., Gardner, R.G.: Exposed hydrophobicity is a key determinant of nuclear quality control degradation. Mol. Biol. Cell 22(13), 2384 2395 (2011). https://doi.org/10.1091/mbc.E11-03-0256

18. Rabbani, N., Thornalley, P.J.: Methylglyoxal, glyoxalase 1 and the dicarbonyl proteome. Amino Acids 42(4), 1133-1142 (2012)

19. Westwood, M.E., Thornalley, P.J.: Molecular characteristics of methylglyoxal-modified bovine and human serum albumins. Comparison with glucose-derived advanced glycation endproduct-modified serum albumins. J. Prot. Chem. 14(5), 359372 (1995)

20. Thornalley, P.J., Rabbani, N.: Protein damage in diabetes and uremia - identifying hotspots of proteome damage where minimal modification is amplified to marked pathophysiological effect. Free Radical Res. 45(1), 89-100 (2010)

21. Rabbani, N., Varma Chittari, M., Bodmer, C.W., Zehnder, D., Ceriello, A., Thornalley, P.J.: Increased glycation and oxidative damage to apolipoprotein B100 of LDL in patients with type 2 diabetes and effect of metformin. Diabetes 59(4), 1038-1045 (2010)

22. Rabbani, N., Godfrey, L., Xue, M., Shaheen, F., Geoffrion, M., Milne, R., Thornalley, P.J.: Conversion of low density lipoprotein to the pro-atherogenic form by methylglyoxal with increased arterial proteoglycan binding and aortal retention. Diabetes 60(7), 1973-1980 (2011)

23. Godfrey, L., Yamada-Fowler, N., Smith, J.A., Thornalley, P.J., Rabbani, N.: Arginine-directed glycation and decreased HDL plasma concentration and functionality. Nutr. Diabetes 4, e134 (2014)

24. Fujimoto, M., Takaki, E., Takii, R., Tan, K., Prakasam, R., Hayashida, N., Iemura, S., Natsume, T., Nakai, A.: RPA assists HSF1 access to nucleosomal DNA by recruiting histone chaperone FACT. Mol. Cell 48(2), 182-194 (2012). https://doi.org/10.1016/j. molcel.2012.07.026

25. Skaggs, H.S., Xing, H., Wilkerson, D.C., Murphy, L.A., Hong, Y., Mayhew, C.N., Sarge, K.D.: HSF1-TPR interaction facilitates export of stress-induced HSP70 mRNA. J. Biol. Chem. 282(47), 33902-33907 (2007). https://doi.org/10.1074/jbc.m704054200

26. Gomez-Pastor, R., Burchfiel, E.T., Thiele, D.J.: Regulation of heat shock transcription factors and their roles in physiology and disease. Nat. Rev. Mol. Cell Biol. 19(1), 4-19 (2018). https://doi.org/ 10.1038/nrm.2017.73

27. Yanagitani, K., Juszkiewicz, S., Hegde, R.S.: UBE2O is a quality control factor for orphans of multiprotein complexes. Science. 357(6350), 472-475 (2017). https://doi.org/10.1126/science. aan 0178

28. Sarkar, A.A., Zohn, I.E.: Hectd1 regulates intracellular localization and secretion of Hsp90 to control cellular behavior of the cranial mesenchyme. J. Cell Biol. 196(6), 789-800 (2012). https://doi.org/ 10.1083/jcb.201105101

29. Chu, B.W., Kovary, K.M., Guillaume, J., Chen, L., Teruel, M.N., Wandless, T.J.: The E3 ubiquitin ligase UBE3C enhances proteasome processivity by ubiquitinating partially proteolyzed substrates. J. Biol. Chem. 288(48), 34575-34587 (2013). https://doi. org/10.1074/jbc.M113.499350

30. $\mathrm{Xu}, \mathrm{Y}$., Anderson, D.E., Ye, Y.: The HECT domain ubiquitin ligase HUWE1 targets unassembled soluble proteins for degradation. Cell Discov. 2, 16040-16040 (2016). https://doi.org/10.1038/celldisc. 2016.40

31. Wang, L., Luk, C.T., Schroer, S.A., Smith, A.M., Li, X., Cai, E.P., Gaisano, H., MacDonald, P.E., Hao, Z., Mak, T.W., Woo, M. Dichotomous role of pancreatic HUWE1/MULE/ARF-BP1 in 
modulating beta cell apoptosis in mice under physiological and genotoxic conditions. Diabetologia. 57(9), 1889-1898 (2014). https://doi.org/10.1007/s00125-014-3295-8

32. Rabbani, N., Thornalley, P.J.: Glyoxalase 1 modulation in obesity and diabetes. Antioxid. Redox Signal. 30, 354-374 (2018). https:// doi.org/10.1089/ars.2017.7424

33. van Well, E.M., Bader, V., Patra, M., Sánchez-Vicente, A., Meschede, J., Furthmann, N., Schnack, C., Blusch, A., Longworth, J., Petrasch-Parwez, E., Mori, K., Arzberger, T., Trümbach, D., Angersbach, L., Showkat, C., Sehr, D.A., Berlemann, L.A., Goldmann, P., Clement, A.M., Behl, C., Woerner, A.C., Saft, C., Wurst, W., Haass, C., Ellrichmann, G., Gold, R., Dittmar, G., Hipp, M.S., Hartl, F.U., Tatzelt, J., Winklhofer, K.F.: A protein quality control pathway regulated by linear ubiquitination. EMBO J. 38(9), e100730 (2019). https://doi. org/10.15252/embj.2018100730

34. Cole, N.B., Ellenberg, J., Song, J., DiEuliis, D., LippincottSchwartz, J.: Retrograde transport of golgi-localized proteins to the ER. J. Cell Biol. 140(1), 1-15 (1998). https://doi.org/10.1083/ jcb.140.1.1

35. Storrie, B., White, J., Röttger, S., Stelzer, E.H., Suganuma, T., Nilsson, T.: Recycling of golgi-resident glycosyltransferases through the ER reveals a novel pathway and provides an explanation for nocodazole-induced Golgi scattering. J. Cell Biol. 143(6), 1505-1521 (1998). https://doi.org/10.1083/jcb.143.6.1505

36. Brandizzi, F., Barlowe, C.: Organization of the ER-Golgi interface for membrane traffic control. Nat. Rev. Mol. Cell Biol. 14(6), 382392 (2013). https://doi.org/10.1038/nrm3588

37. Borgese, N.: Getting membrane proteins on and off the shuttle bus between the endoplasmic reticulum and the Golgi complex. J. Cell Sci. 129(8), 1537-1545 (2016). https://doi.org/10.1242/jcs.183335

38. Yamazaki, H., Hiramatsu, N., Hayakawa, K., Tagawa, Y., Okamura, M., Ogata, R., Huang, T., Nakajima, S., Yao, J., Paton, A.W., Paton, J.C., Kitamura, M.: Activation of the Akt-NF-kappaB pathway by subtilase cytotoxin through the ATF6 branch of the unfolded protein response. J. Immunol. (Baltimore, Md.: 1950) 183(2), 1480-1487 (2009). https://doi.org/10.4049/jimmunol. 0900017

39. Janssens, S., Pulendran, B., Lambrecht, B.N.: Emerging functions of the unfolded protein response in immunity. Nat. Immunol. 15(10), 910-919 (2014). https://doi.org/10.1038/ni.2991

40. Paneni, F., Costantino, S., Battista, R., Castello, L., Capretti, G., Chiandotto, S., Scavone, G., Villano, A., Pitocco, D., Lanza, G., Volpe, M., Lüscher, T.F., Cosentino, F.: Adverse epigenetic signatures by histone methyltransferase Set7 contribute to vascular dysfunction in patients with type 2 diabetes mellitus. Circ. Cardiovasc. Genet. 8(1), 150-158 (2015). https://doi.org/10.1161/circgenetics. 114.000671

41. Chen, J., Guo, Y., Zeng, W., Huang, L., Pang, Q., Nie, L., Mu, J., Yuan, F., Feng, B.: ER stress triggers MCP-1 expression through SET7/9-induced histone methylation in the kidneys of $\mathrm{db} / \mathrm{db}$ mice. Am. J. Physiol. Renal Physiol. 306(8), F916-F925 (2014). https:// doi.org/10.1152/ajprenal.00697.2012

42. Okabe, J., Orlowski, C., Balcerczyk, A., Tikellis, C., Thomas, M.C., Cooper, M.E., El-Osta, A.: Distinguishing hyperglycemic changes by Set7 in vascular endothelial cells. Circ. Res. 110(8), 1067-1076 (2012). https://doi.org/10.1161/circresaha.112.266171

43. El-Osta, A., Brasacchio, D., Yao, D., Pocai, A., Jones, P.L., Roeder, R.G., Cooper, M.E., Brownlee, M.: Transient high glucose causes persistent epigenetic changes and altered gene expression during subsequent normoglycemia. J. Exp. Med. 205(10), 2409-2417 (2008)

44. Lerner, A.G., Upton, J.-P., Praveen, P.V.K., Ghosh, R., Nakagawa, Y., Igbaria, A., Shen, S., Nguyen, V., Backes, B.J., Heiman, M., Heintz, N., Greengard, P., Hui, S., Tang, Q., Trusina, A., Oakes, S.A., Papa, F.R.: IRE $1 \alpha$ induces thioredoxin-interacting protein to activate the NLRP3 inflammasome and promote programmed cell death under irremediable ER stress. Cell Metabol. 16(2), 250-264 (2012). https://doi.org/10.1016/j.cmet.2012.07.007

45. Waldhart, A.N., Dykstra, H., Peck, A.S., Boguslawski, E.A., Madaj, Z.B., Wen, J., Veldkamp, K., Hollowell, M., Zheng, B., Cantley, L.C., McGraw, T.E., Wu, N.: Phosphorylation of TXNIP by AKT Mediates Acute Influx of Glucose in Response to Insulin. Cell Rep. 19(10), 2005-2013. https://doi.org/10.1016/j. celrep.2017.05.041

46. Oslowski, C.M., Hara, T., O’Sullivan-Murphy, B., Kanekura, K., Lu, S., Hara, M., Ishigaki, S., Zhu, L.J., Hayashi, E., Hui, S.T., Greiner, D., Kaufman, R.J., Bortell, R., Urano, F.: Thioredoxininteracting protein mediates ER stress-induced $\beta$ cell death through initiation of the inflammasome. Cell Metabol. 16(2), 265-273 (2012). https://doi.org/10.1016/j.cmet.2012.07.005

47. Jo, S.H., Kim, M.Y., Park, J.M., Kim, T.H., Ahn, Y.H.: Txnip contributes to impaired glucose tolerance by upregulating the expression of genes involved in hepatic gluconeogenesis in mice. Diabetologia. 56(12), 2723-2732 (2013). https://doi.org/10.1007/ s00125-013-3050-6

48. Glass, O., Henao, R., Patel, K., Guy, C.D., Gruss, H.J., Syn, W.-K., Moylan, C.A., Streilein, R., Hall, R., Mae Diehl, A., Abdelmalek, M.F.: Serum interleukin-8, osteopontin, and monocyte chemoattractant protein 1 are associated with hepatic fibrosis in patients with nonalcoholic fatty liver disease. Hepatol. Commun. 2(11), 1344-1355 (2018). https://doi.org/10.1002/hep4.1237

49. Haukeland, J.W., Damås, J.K., Konopski, Z., Løberg, E.M., Haaland, T., Goverud, I., Torjesen, P.A., Birkeland, K., Bjøro, K., Aukrust, P.: Systemic inflammation in nonalcoholic fatty liver disease is characterized by elevated levels of CCL2. J. Hepatol. 44(6), 1167-1174 (2006). https://doi.org/10.1016/j.jhep.2006.02. 011

50. Ajmera, V., Perito, E.R., Bass, N.M., Terrault, N.A., Yates, K.P., Gill, R., Loomba, R., Diehl, A.M., Aouizerat, B.E.: Novel plasma biomarkers associated with liver disease severity in adults with nonalcoholic fatty liver disease. Hepatology. 65(1), 65-77 (2017). https://doi.org/10.1002/hep.28776

51. Spoto, B., Pisano, A., Zoccali, C.: Insulin resistance in chronic kidney disease: a systematic review. Am. J. Physiol. Renal Physiol. 311(6), F1087-F1108 (2016). https://doi.org/10.1152/ ajprenal.00340.2016

52. Haller, H., Bertram, A., Nadrowitz, F., Menne, J.: Monocyte chemoattractant protein-1 and the kidney. Curr. Opin. Nephrol. Hypertens. 25(1), 42-49 (2016)

53. Reynolds, C.J., Quigley, K., Cheng, X., Suresh, A., Tahir, S., Ahmed-Jushuf, F., Nawab, K., Choy, K., Walker, S.A., Mathie, S.A., Sim, M., Stowell, J., Manji, J., Pollard, T., Altmann, D.M., Boyton, R.J.: Lung defense through IL-8 carries a cost of chronic lung remodeling and impaired function. Am. J. Respir. Cell Mol. Biol. 59(5), 557-571 (2018). https://doi.org/10.1165/rcmb.2018$0007 \mathrm{OC}$

54. Valentine, M.S., Link, P.A., Herbert, J.A., Kamga Gninzeko, F.J., Schneck, M.B., Shankar, K., Nkwocha, J., Reynolds, A.M., Heise, R.L.: Inflammation and monocyte recruitment due to aging and mechanical stretch in alveolar epithelium are inhibited by the molecular chaperone 4-phenylbutyrate. Cell. Mol. Bioeng. 11(6), 495508 (2018). https://doi.org/10.1007/s12195-018-0537-8

55. Lee, Y.B., Kim, Y.S., Lee, D.-H., Kim, H.Y., Lee, J.-I., Ahn, H.-S., Sohn, T.S., Lee, T.-K., Song, J.Y., Yeo, C.D., Hong, M., Han, K., Jeong, S.C., Chae, H.S.: Association between HOMA-IR and lung function in Korean young adults based on the Korea National Health and Nutrition Examination Survey. Sci. Rep. 7(1), 11726 (2017). https://doi.org/10.1038/s41598-017-11337-3

56. Moreno Velásquez, I., Gajulapuri, A., Leander, K., Berglund, A., de Faire, U., Gigante, B.: Serum IL8 is not associated with cardiovascular events but with all-cause mortality. BMC Cardiovasc. 
Disord. 19(1), 34 (2019). https://doi.org/10.1186/s12872-0191014-6

57. Piemonti, L., Calori, G., Lattuada, G., Mercalli, A., Ragogna, F., Garancini, M.P., Ruotolo, G., Luzi, L., Perseghin, G.: Association between plasma monocyte chemoattractant protein-1 concentration and cardiovascular disease mortality in middle-aged diabetic and nondiabetic individuals. Diabetes Care 32(11), 2105-2110 (2009). https://doi.org/10.2337/dc09-0763

58. Ausk, K.J., Boyko, E.J., Ioannou, G.N.: Insulin resistance predicts mortality in nondiabetic individuals in the U.S. Diabetes Care. 33(6), 1179-1185 (2010). https://doi.org/10.2337/dc09-2110

59. Xue, M., Rabbani, N., Momiji, H., Imbasi, P., Anwar, M.M., Kitteringham, N.R., Park, B.K., Souma, T., Moriguchi, T., Yamamoto, M., Thornalley, P.J.: Transcriptional control of glyoxalase 1 by Nrf2 provides a stress responsive defence against dicarbonyl glycation. Biochem. J. 443(1), 213-222 (2012)

60. Park, M.H., Kinra, S., Ward, K.J., White, B., Viner, R.M.: Metformin for obesity in children and adolescents: a systematic review. Diabetes Care 32(9), 1743-1745 (2009). https://doi.org/ $10.2337 / \mathrm{dc} 09-0258$

61. Mancini, M.C., Halpern, A.: Orlistat in the prevention of diabetes in the obese patient. Vasc. Health Risk Manag. 4(2), 325-336 (2008)

62. Hanusch-Enserer, U., Cauza, E., Spak, M., Endler, G., Dunky, A., Tura, A., Wagner, O., Rosen, H.R., Pacini, G., Prager, R.: Improvement of insulin resistance and early atherosclerosis in patients after gastric banding. Obes. Res. 12(2), 284-291 (2004)

63. Tirosh, A., Shai, I., Tekes-Manova, D., Israeli, E., Pereg, D., Shochat, T., Kochba, I., Rudich, A.: Normal fasting plasma glucose levels and type 2 diabetes in young men. N. Engl. J. Med. 353(14), 1454-1462 (2005). https://doi.org/10.1056/NEJMoa050080

64. Bruun, J.M., Verdich, C., Toubro, S., Astrup, A., Richelsen, B.: Association between measures of insulin sensitivity and circulating levels of interleukin-8, interleukin-6 and tumor necrosis factor-alpha. Effect of weight loss in obese men. Eur. J. Endocrinol. 148(5), 535-542 (2003). https://doi.org/10.1530/eje.0.1480535

65. Tahrani, A.A.: Novel therapies in type 2 diabetes: insulin resistance. Practical Diabetes. 34(5), 161-166a (2017). https://doi.org/10. 1002/pdi.2109

66. Cariou, B., Charbonnel, B., Staels, B.: Thiazolidinediones and PPAR $\gamma$ agonists: time for a reassessment. Trends Endocrinol. Metab. 23(5), 205-215 (2012). https://doi.org/10.1016/j.tem. 2012.03.001
67. Hetz, C., Chevet, E., Oakes, S.A.: Proteostasis control by the unfolded protein response. Nat. Cell Biol. 17(7), 829-838 (2015). https://doi.org/10.1038/ncb3184

68. Smith, M.C., Scaglione, K.M., Assimon, V.A., Patury, S., Thompson, A.D., Dickey, C.A., Southworth, D.R., Paulson, H.L., Gestwicki, J.E., Zuiderweg, E.R.P.: The E3 ubiquitin ligase CHIP and the molecular chaperone Hsc70 form a dynamic, tethered complex. Biochemistry 52(32), 5354-5364 (2013). https://doi.org/10. 1021/bi4009209

69. Stricher, F., Macri, C., Ruff, M., Muller, S.: HSPA8/HSC70 chaperone protein: structure, function, and chemical targeting. Autophagy. 9(12), 1937-1954 (2013). https://doi.org/10.4161/ auto.26448

70. Fernández-Fernández, M.R., Gragera, M., Ochoa-Ibarrola, L., Quintana-Gallardo, L., Valpuesta, J.M.: Hsp70 - a master regulator in protein degradation. FEBS Lett. 591(17), 2648-2660 (2017). https://doi.org/10.1002/1873-3468.12751

71. Ito, Y., Ando, A., Ando, H., Ando, J., Saijoh, Y., Inoko, H., Fujimoto, H.: Genomic structure of the spermatid-specific Hsp70 homolog gene located in the class III region of the major histocompatibility complex of mouse and man1. J. Biochem. 124(2), 347353 (1998). https://doi.org/10.1093/oxfordjournals.jbchem. a022118

72. Zuo, D., Subjeck, J., Wang, X.-Y.: Unfolding the role of large heat shock proteins: new insights and therapeutic implications. Front. Immunol. 7(75) (2016). https://doi.org/10.3389/fimmu.2016.00075

73. Lee, A.S.: Glucose-regulated proteins in cancer: molecular mechanisms and therapeutic potential. Nat. Rev. Cancer. 14(4), 263-276 (2014). https://doi.org/10.1038/nrc3701

74. Takayama, S., Xie, Z., Reed, J.C.: An evolutionarily conserved family of Hsp70/Hsc70 molecular chaperone regulators. J. Biol. Chem. 274(2), 781-786 (1999). https://doi.org/10.1074/jbc.274.2. 781

75. Xylourgidis, N., Fornerod, M.: Acting out of character: regulatory roles of nuclear pore complex proteins. Dev. Cell 17(5), 617-625 (2009). https://doi.org/10.1016/j.devcel.2009.10.015

Publisher's Note Springer Nature remains neutral with regard to jurisdictional claims in published maps and institutional affiliations. 